\title{
Geomagnetic and ionospheric data analysis over Antarctica: a contribution to the long term trends investigation
}

\author{
L. Alfonsi, G. De Franceschi, and A. De Santis \\ Istituto Nazionale di Geofisica e Vulcanologia, Via di Vigna Murata, 605, 00143 Rome, Italy \\ Received: 10 May 2007 - Revised: 6 September 2007 - Accepted: 6 November 2007 - Published: 28 May 2008
}

\begin{abstract}
The analysis of the $f o F 2$ ionosonde data acquired at mid and high latitudes reveals a general decreasing of the F2 plasma frequency over more than two solar cycles, showing steeper trends over the high latitude stations and, in particular, over Antarctica. A careful analysis of the $f o F 2$ hourly data, opportunely catalogued in different levels of magneto-ionospheric conditions, highlights the role of the geomagnetic activity in the secular change of the ionosphere and confirms the latitudinal dependence of the trends. These results suggest interesting relations with some recent findings on the rapid decrease of some important physical and statistical quantities related to the geomagnetic field over the whole globe and mainly in Antarctica. In this paper we discuss the possibility of a connection between the ionospheric trends and a possible imminent geomagnetic reversal or excursion.
\end{abstract}

Keywords. Ionosphere (Polar ionosphere) - Geomagnetism and paleomagnetism (Time variations, secular and long term) - Radio science (Nonlinear phenomena)

\section{Introduction}

Long term changes of the middle-upper atmosphere and the role of their natural and anthropogenic causes have been recently reviewed by Lastovicka (2005) and Bremer (2005). In the past few years several authors focused their investigations on the geomagnetic activity as the primary natural reason of the ionospheric observed trends (see, e.g., Danilov, 2001; Mikhailov and Marin, 2000). Contemporary, longterm changes of the geomagnetic activity were deeply investigated by analysing the secular behaviour of the most popular and long-life geomagnetic indices, mainly aa and Ap (Clilverd et al., 1998; Lockwood and Stamper, 1999; Cliver and Ling, 2002; Richardson et al., 2002; Gulyaeva, 2002;

Correspondence to: L. Alfonsi

(lucilla.alfonsi@ingv.it)
Clilverd et al., 2005; Mursula and Martini, 2006). The results indicate a possible increase of the geomagnetic activity during the XX century but the matter is quite debated: Clilverd and his co-authors (1998) indicate an enhancement in the number of magnetic storms; Gulyaeva (2002) find a lowering in the occurrence of the aa index quiet condition; Cliver and Ling (2002) claimed that only during the first half of the XX century the aa index shows an increasing trend. Recently Clilverd et al. (2005) and Musula and Martini (2006) investigated again the long-term change of the aa index through the use of a new tool introduced by Svalgaard et al. (2004): the IHV (Inter Hour Variability) index. It is defined as an average of the six absolute differences of the successive hourly values of the $\mathrm{H}$ component between 19:00 and 01:00 local time (LT) and its use allows the reproduction and verification of the aa index, otherwise impossible as the original measurements do not exist in digital format. Since the hourly values of the measured magnetic field are available in digital format in the World Data Centers for several stations, the IHV index can be easily calculated and adopted to measure the centennial change of the geomagnetic activity. Clilverd et al. (2005) and Mursula and Martini (2006) quantified the long-term increase of the geomagnetic activity discussing the role of the changes in the external conditions and in the secular decrease of the geomagnetic moment. The weakening of the Earth's magnetic dipole is the protagonist of several papers (e.g. Gubbins et al., 2006; De Santis et al., 2004). These works are mainly devoted to the investigation of the typical time scale associated to a possible reversal (or excursion) of the Earth's magnetic field. In their paper Rajaram et al. (2002) found a rapid decrease in total magnetic field over a large part of Antarctica pointing out this is as a region of possible reverse magnetic flux. These intriguing findings are confirmed by a recent analysis (De Santis, 2007) showing that the geomagnetic field over Antarctica is decreasing faster than on global scale. 
Table 1. The ionospheric observatories under investigation.

\begin{tabular}{lccc}
\hline STATION & $\begin{array}{c}\text { GEOGRAPHIC } \\
\text { CO-ORDINATES }\end{array}$ & $\begin{array}{c}\text { GEOMAGNETIC } \\
\text { CO-ORDINATES }\end{array}$ & $\begin{array}{c}\text { PERIOD } \\
\text { UNDER } \\
\text { INVESTIGATION }\end{array}$ \\
\hline Lycksele & $64.6^{\circ} \mathrm{N} 18.8^{\circ} \mathrm{E}$ & $62.5^{\circ} \mathrm{N} 111.7^{\circ} \mathrm{E}$ & $1957-1998$ \\
Juliusruh & $54.6^{\circ} \mathrm{N} 13.4^{\circ} \mathrm{E}$ & $54.3^{\circ} \mathrm{N} 99.7^{\circ} \mathrm{E}$ & $1974-1998$ \\
Slough & $51.5^{\circ} \mathrm{N} 359.4^{\circ} \mathrm{E}$ & $54.0^{\circ} \mathrm{N} 84.4^{\circ} \mathrm{E}$ & $1957-1998$ \\
Rome & $41.8^{\circ} \mathrm{N} 12.5^{\circ} \mathrm{E}$ & $42.3^{\circ} \mathrm{N} 93.2^{\circ} \mathrm{E}$ & $1976-1998$ \\
Boulder & $40.0^{\circ} \mathrm{N} 254.7^{\circ} \mathrm{E}$ & $48.9^{\circ} \mathrm{N} 318.7^{\circ} \mathrm{E}$ & $1960-1998$ \\
Mawson & $67.6^{\circ} \mathrm{S} 62.9^{\circ} \mathrm{E}$ & $73.3^{\circ} \mathrm{S} 105.1^{\circ} \mathrm{E}$ & $1962-1998$ \\
\hline
\end{tabular}

The geomagnetic control on F2 layer is well known and the possible positive trend of the geomagnetic activity could be connected with the ionospheric trends already found (Bremer, 1992; Mikhailov and Marin, 2000; Alfonsi et al., 2002). To contribute to this general discussion, it could be useful to consider different scientific tools to investigate the longterm geomagnetic effect on the ionosphere. In this frame, after the papers by De Franceschi et al. (2002) and Alfonsi et al. (2002), a new approach to isolate the foF 2 data corresponding to quiet magnetic condition is proposed to investigate its secular behaviour. The original tool here used is termed MACap (Magnetic Activity Catalogue for ionospheric applications) and it has been introduced to characterize the impact of the magnetic disturbance on the ionosphere (De Franceschi et al., 1999). Its adoption in this work should allow a better reproduction of the non-linear relationship between the foF 2 and $a p$ variations.

This paper is organized as follows: the method of the data selection and processing is described in Sect. 2; the results are shown and discussed in Sect. 3 in the light of the recent findings on the possible imminent reversal or excursion of the geomagnetic field whose effects are so evident over Antarctica; the conclusions are reported in Sect. 4.

\section{Method}

The foF 2 data here analysed have been acquired by some ionospheric stations located at mid and high latitude regions along more than two solar cycles (Table 1). The method adopted to analyse the $f o F 2$ data was derived from Bremer (1992) and has been successively used by several authors (see, e.g., Lastovicka et al., 2006). The main steps of our data selection and processing are the followings:

a) Selection of the "full-weight" foF2 hourly data, i.e. not accompanied by qualifying letters:

After the encouraging results obtained in our previous work (Alfonsi et al., 2002) we continue to adopt this criterion to eliminate possible sources of error, due to physical phenom- ena and/or to technical problems, that could influence the final results. For this aim we have considered only those hourly foF 2 data that are not accompanied by qualifier letters (Piggott and Rawer, 1972; Ulich et al., 2003).

\section{b) Selection of the foF 2 hourly data corresponding to quiet magnetic condition $(M A C a p=0)$ :}

We have tried to remove the magnetic influences from the foF 2 measurements by selecting only those data corresponding to quiet magneto-ionospheric conditions. To do that we have used a new tool, termed MACap, introduced to reproduce the non-linear relationship between the magnetic disturbance, indicated by the ap index, and its impact on the ionosphere, indicated by the $f o F 2$ (De Franceschi et al., 1999). Wrenn (1987) and then other authors (Perrone and De Franceschi, 1999; Perrone et al., 2001) have shown that the correlation between geomagnetic indices and ionospheric parameters improves when the time-series accumulation of the magnetic index is used instead of the index apart. In the case of ap index its time-series accumulation reads:

$a p(\tau)=(1-\tau)\left[a p_{0}+(\tau) a p_{-1}+(\tau)^{2} a p_{-2}+\ldots\right]$

being $a p$ a tree-hours index, $a p_{-1}, a p_{-2}$, etc., related to the previous three hours, six hours and so on, and $\tau$ a persistence factor, ranged between 0 and 1 , corresponding to the response-recovery time of the ionosphere to magnetic perturbations (for details see Wrenn, 1987; Perrone and De Franceschi, 1999). After some investigations based on foF2 data from mid latitude (Wu and Wilkinson, 1995) and high latitude (Perrone and De Franceschi, 1999) stations, the correlation analysis shows better results if $\tau$ is equal to 0.8 , corresponding to a response time of the ionosphere of about $15 \mathrm{~h}$. On the basis of $a p(0.8)$, i.e. $a p(\tau)$ according to Eq. (1) with $\tau=0.8$, De Franceschi et al. (1999) have characterized the magnetic activity impact on the ionosphere by introducing MACap(0.8) (Magnetic Activity Catalogue for ionospheric applications), hereafter simply MACap, defined according to four levels of $a p(0.8)$ values, as reported in Table 2 . 
Table 2. Correspondence between the $a p(0.8)$ values and four levels of magnetic activity defining the MACap.

\begin{tabular}{ccc}
\hline $\begin{array}{c}a p(0.8) \\
\text { INTERVAL LIMITS }\end{array}$ & $\begin{array}{c}\text { LEVELS DEFINITION } \\
\text { OF MAGNETIC } \\
\text { CONDITION }\end{array}$ & $\begin{array}{c}\text { MACap }(\tau=0.8) \\
\text { CORRESPONDING } \\
\text { LEVELS }\end{array}$ \\
\hline $0<a p(0.8) \leq 7$ & Quiet & 0 \\
$7<a p(0.8) \leq 20$ & Slightly Disturbed & 1 \\
$20<a p(0.8) \leq 32$ & Moderately Disturbed & 2 \\
ap $(0.8)>32$ & Severely Disturbed & 3 \\
\hline
\end{tabular}

The importance of MACap stands in its efficiency in reproducing the impact of the geomagnetic activity on the ionosphere and, in particular, on the F2 layer plasma frequency (De Franceschi et al., 2002).

We have used the 0 level of MACap, i.e. the quiet magnetic condition (Table 2), as selecting criterion to isolate the hourly foF 2 data not affected by magnetic perturbation.

c) Re-calculation of the foF 2 medians on the data obtained after $a$ ) and $b$ ):

The $f o F 2$ medians are re-calculated on the basis of the hourly values obtained after the application of the points $a$ ) and $b$ ). To compute the medians at least 5 values, corresponding to the same hour of the same month and of the same year, are necessary.

d) Application of a $\left(R, R^{2}\right)$ regression model to remove the solar influence from the foF 2 observations:

$f o F 2_{h, m, y}(\bmod )=a_{h, m}+b_{h, m} \cdot R_{m, y}+c_{h, m} \cdot R_{m, y}^{2}$

A regression model, given by Eq. (2) is derived from experimental monthly median values $f o F 2 h, m, y$ (exp) (according to point $c$ )) for a given hour, $h$, month, $m$, and year, $y ; R_{\mathrm{m}, \mathrm{y}}$ is the R12 sunspot number for a given month, $\mathrm{m}$ and year, $\mathrm{y}$ and the coefficients $a_{h, m}, b_{h, m}$ and $c_{h, m}$ are obtained according to the least squared method.

This regression is adopted to reproduce the $f o F 2$ variation due to solar cycle effect and, consequently, should be useful to remove this effect from the observations.

\section{e) Calculation of the residual of foF2:}

The $f o F 2$ residuals are obtained by subtracting $f o F 2$ (mod) from $f o F 2(\exp )$ :

$$
\Delta f o F 2_{h, m, y}=f o F 2_{h, m, y}(\exp )-f o F 2_{h, m, y}(\bmod )
$$

Table 3. Total $f o F 2$ trend rates $(D f o F 2)$ obtained along more than two solar cycles of observations made by mid and high latitude ionospheric stations (in red) and their respective yearly trend rates $(d f o F 2)$. Both the quantities are referred to quiet magnetic conditions.

\begin{tabular}{lcc}
\hline STATION & $\begin{array}{c}\text { DfoF } 2 \pm \Delta D f o F 2 \\
(\mathrm{MHz})\end{array}$ & $\begin{array}{c}\text { dfoF2 } \pm \Delta d f o F 2 \\
(\mathrm{MHz} / \mathrm{year})\end{array}$ \\
\hline Lycksele & $-0.10 \pm 0.10$ & $-0.002 \pm 0.002$ \\
Juliusruh & $-0.11 \pm 0.11$ & $-0.004 \pm 0.004$ \\
Slough & $-0.15 \pm 0.15$ & $-0.003 \pm 0.003$ \\
Rome & $-0.20 \pm 0.12$ & $-0.009 \pm 0.005$ \\
Boulder & $-0.17 \pm 0.14$ & $-0.004 \pm 0.003$ \\
Mawson & $-0.18 \pm 0.13$ & $-0.005 \pm 0.004$ \\
\hline
\end{tabular}

\section{f) Evaluation of the long-term trend of $\triangle$ foF 2 and its error:}

On the base of the yearly means of the $f o F 2$ residuals (Eq. 3) the long-term trend is derived as the $b_{y}$ of the linear relationship:

$$
\triangle f o F 2_{y}=a_{y}+b_{y} \cdot\left(Y_{b}-Y\right)
$$

where $\triangle f o F 2_{y}$ is the yearly mean of the $\Delta f o F 2_{h, m, y} ; a_{y}$ and $b_{y}$ are regression coefficients; $Y_{b}$ and $Y$ are the beginning year and each year of the data series considered, respectively. The $b_{y}$ coefficient gives the $f o F 2$ yearly trend rate. The total trend rate $D f 0 F 2$, is obtained by multiplying $b_{y}$ for the length of the data series considered. The error on the trend rate is simply given by the standard deviation on $b_{y}$ (for details see Alfonsi et al., 2002).

\section{Results and discussion}

The results obtained after the analysis described above indicate a general decrease of the F2 plasma frequency under quiet magneto-ionospheric conditions (Fig. 1). The negative trend rates $D f 0 F 2$ over the entire period under investigation (Table 1) are reported in the second column of Table 3. To avoid any confusion due to the different length of the data series considered, the yearly trend rates $d f o F 2$ (in $\mathrm{MHz} /$ year) are listed in the last column of the same table. For sake of comparison in Table 4 are reported the maximum and minimum trends obtained in our previous works, through the analysis of $f o F 2$ hourly and monthly median data from mid and high latitude stations carried out without any consideration of magneto-ionospheric conditions (Alfonsi et al., 2001, 2002). The range of the trend rates expressed by the maximum and minimum values reported in Table 4 is due to the different regression models adopted (Alfonsi et al., 2001, 2002). Similarly to Table 3 , the maximum and minimum values of the yearly trend rates $d f o F 2$ (in MHz/year) are listed in the last column. 
Table 4. Maximum and minimum $f o F 2$ trend rates ( $\max -\min D f o F 2$ ) obtained along more than two solar cycles of observations made by mid and high latitude ionospheric stations (in red) and their respective yearly trend rates (max-min $d f o F 2$ ). Both the quantities are referred to all the magnetic conditions and are obtained with the use of different regression models (adapted from Alfonsi et al., 2001, 2002).

\begin{tabular}{llcc}
\hline STATION & foF2 ANALYSED & $\begin{array}{c}\text { max-min } D f o F 2 \\
\text { (MHz) }\end{array}$ & $\begin{array}{c}\text { max-min } d f o F 2 \\
\text { (MHz/year) }\end{array}$ \\
\hline Lycksele & Hourly & $-0.26 \div 0.10$ & $-0.006 \div 0.002$ \\
Juliusruh & Hourly & -0.11 & -0.005 \\
Slough & Hourly & $-0.11 \div-0.06$ & $-0.003 \div-0.001$ \\
Rome & Hourly & $-0.15 \div-0.03$ & $-0.007 \div-0.001$ \\
Boulder & Hourly & -0.17 & -0.004 \\
Terre Adelie & Monthly Medians & $-0.47 \div-0.16$ & $-0.014 \div-0.005$ \\
Mawson & Hourly & $-0.45 \div-0.18$ & $-0.012 \div-0.005$ \\
& Monthly Medians & $-0.82 \div-0.50$ & $-0.022 \div-0.014$ \\
Syowa & Monthly Medians & $-0.92 \div-0.22$ & $0.028 \div-0.007$ \\
\hline
\end{tabular}

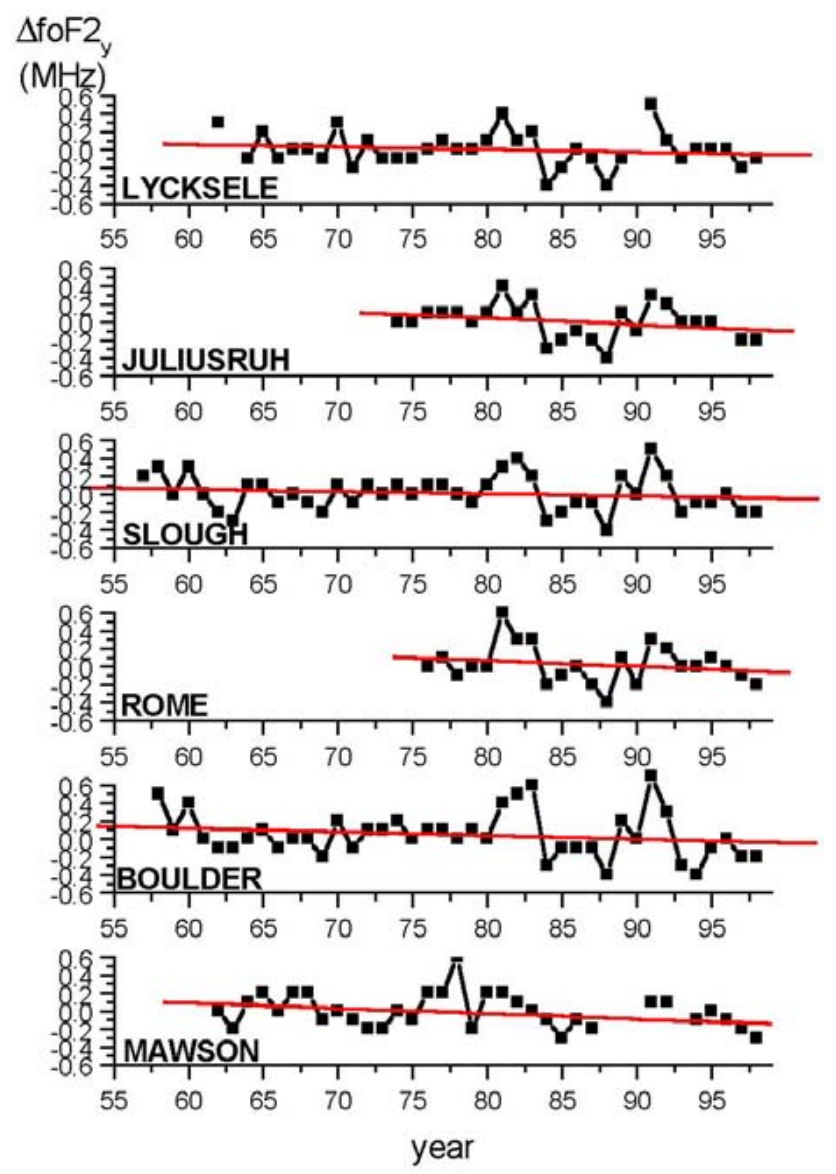

Fig. 1. Yearly $f o F 2$ residuals $\left(\triangle f o F 2_{y}\right)$ for each ionospheric station considered.

The comparison between Tables 3 and 4 confirms a strongest trend over Antarctica and highlights the crucial role of the geomagnetic activity in the trend estimate at high lati- tudes. In fact, Lycksele and, above all, Mawson show significant differences when the magnetic condition is taken into account. Unfortunately Terre Adelie and Syowa do not have hourly data complete with qualifying and descriptive letters for the period under investigation, so it is not possible to treat their observations as described in Sect. 1, step $a$.

From our findings a question comes up: why are the foF 2 long-term trends are always stronger over Antarctica? The suspicion is that a deep investigation of the foF 2 changes at high latitudes of the southern hemisphere could reveal an important influence of the regional variation of the geomagnetic field. The reason of this suspicion is suggested in a paper by De Santis et al. (2004) dedicated to the analysis of certain statistical quantities, such as the Information Content $I(t)$ (Shannon, 1948), of the Earth's magnetic field. Among all considered quantities, they evaluate the mean square value of the geomagnetic field over the whole globe, as given by the spherical harmonics expansion of the geomagnetic potential $V$ (Lowes, 1966; De Santis et al., 1995):

$$
\begin{aligned}
\left\langle B^{2}(t)\right\rangle= & \frac{1}{4 \pi} \int_{0}^{\pi} \int_{0}^{2 \pi} B^{2}(\theta, \lambda, t) \sin \theta d \theta d \lambda= \\
& \sum_{n=1}^{N}(n+1) \sum_{m=0}^{n}\left(g_{n}^{m}\right)^{2}+\left(h_{n}^{m}\right)^{2}
\end{aligned}
$$

in which $\theta, \lambda$ and $t$ are colatitude, longitude and time, respectively; $g_{n}^{m}, h_{n}^{m}$ are the Gauss coefficients of the spherical harmonic expansion of the geomagnetic potential $V$, such as $B=-\operatorname{grad} V ; m, n$ are the spherical harmonics order and degree, respectively. Extrapolating linearly the behaviour of $<B^{2}>$ from 1900 to 2000 , as given by the global model IGRF (Macmillan and Maus, 2005), De Santis and co-authors (2004) estimate that its zero value will occur by around 1000 years.

Starting from the assumption that each region of the Earth surface contributes differently to $<B^{2}>$ (Eq. 5), De Santis 
(2007) chooses a spherical cap of a model valid for the Antarctic region below $60^{\circ} \mathrm{S}$ (i.e. a cap centered at the south geographic pole with a maximal co-latitude $\Theta 0=30^{\circ}$ ), the socalled Antarctic Reference Model (ARM; De Santis et al., 2002; Gaya-Piqué et al., 2006). In this way it is possible to extrapolate the behavior of $\left\langle B^{2}(t)\right\rangle_{\theta_{0}}$ over Antarctica, predicting its zero value by around 340 years from now. In Fig. 2a we show the temporal behaviour between 1900 and 2000 of the global magnetic energy density, $\varepsilon$, (in $\mathrm{mJ}_{\text {per }} \mathrm{m}^{3}$ ) given by (i.e. a cap centered at the south geographic pole with a maximal co-latitude $\Theta_{0}=30^{\circ}$ ):

$\varepsilon=\frac{1}{2} \frac{<B^{2}>}{\mu_{0}}$

Similarly in Fig. $2 b$ is plotted the Antarctic contribution to the magnetic energy density $\varepsilon_{\theta_{0}}$, given by:

$\varepsilon_{\theta_{0}}=\frac{1}{2} \frac{<B_{\theta_{0}}^{2}>}{\mu_{0}}$

where the decaying trend is more accentuated, providing an even closer estimation of $\varepsilon_{\theta_{0}}=0$ by 340 years. This confirms that the present phenomenon of rapid geomagnetic field decay is contributed more by the southern hemisphere (Gubbins, 1987; Gubbins et al., 2006; De Santis, 2007).

Which is the influence of the weakening of the magnetic dipole on the long-term variation of the geomagnetic activity? Secular changes in the geomagnetic field influence the ionospheric conductivity (Rishbeth, 1985, 1997), affecting the magnetic signature at the ground. Consequently a possible reversal or excursion of the geomagnetic field should be visible in the long term behaviour of the geomagnetic indices, e.g. $a a$, accounting the ionospheric response to a decrease of the Earth's magnetic dipole momentum. According to some recent investigations (Clilverd et al., 2002, 2005) the contribution of this decrease is practically negligible, while for other authors (Mursula and Martini, 2006) this aspect should be taken more into account. After the findings by De Santis (2007) our next step will be to explore with more details the possibility, analysing $f o F 2$ data over a spherical cap including Antarctica. The application of the spherical harmonics expansion to the $f o F 2$ data has been already adopted to reconstruct the ionosphere on regional scale (De Santis et al., 1992; De Franceschi et al., 1994). Following the same approach, we should be able to investigate the present and future behaviour of the F2 plasma frequency in the same manner adopted by De Santis et al. (2004). Their method should allow the confirmation of the $f o F 2$ long-term trends (if any), providing, at the same time, an estimate of their typical timescale.

\section{Conclusions}

In this paper we have analysed the $f o F 2$ hourly data acquired by mid and high latitude stations along more than two a)

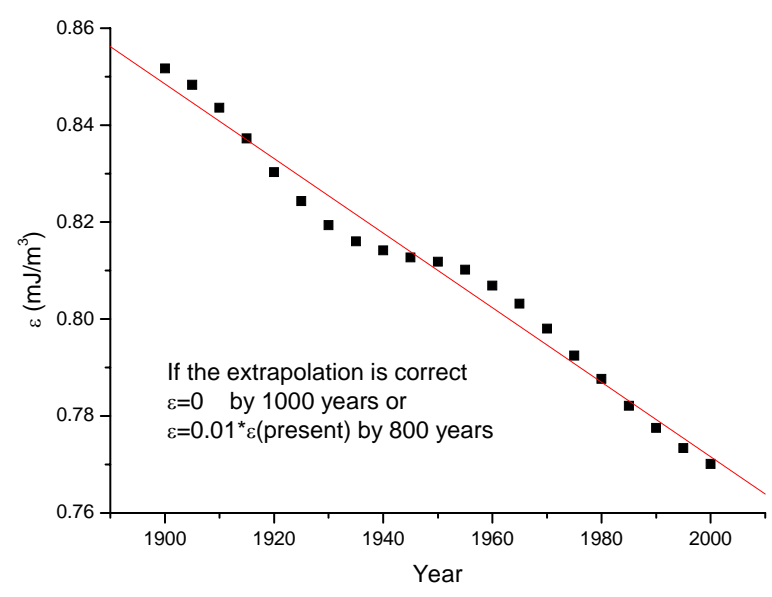

b)

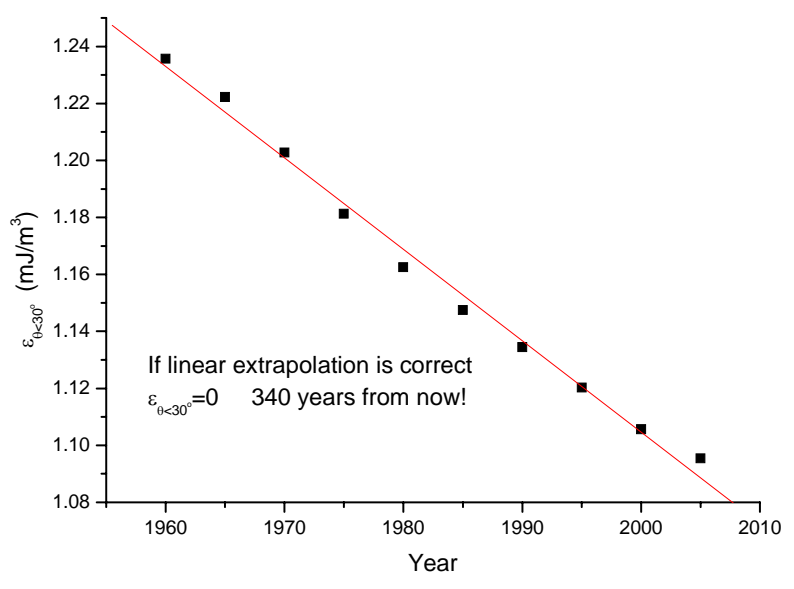

Fig. 2. (a) Global magnetic energy density; (b) Contribution of Antarctica Region to the magnetic energy density.

solar cycles. We have re-calculated their medians on the base of the reliability of the measurements, considering only those values not accompanied by qualifying and descriptive letters, and on a selection of the magneto-ionospheric conditions, as given by the quiet level of the MACap catalogue. Our findings can be summarised as follows:

1. Confirmation of a general decreasing trend of the F2 plasma frequency more evident over Antarctica, independent of the length of the data series considered, highlighting a latitudinal effect.

2. Evidence of the crucial role played by the geomagnetic activity influence on the observed trends as emphasized by the use of the magneto-ionospheric catalogue MACap: under quiet magnetic conditions the 
ionospheric trends are smoothed, above all over Antarctica.

3. Speculation on the possible correlation between the ionospheric trends and the excursion (or reversal?) of the geomagnetic field. Geomagnetic polarity transitions, leading to a weakening of the magnetosphere shield, could strongly affect high energetic particle fluxes into the upper atmosphere.

Since the apparent correlation between the rapid decrease of geomagnetic dipole and the strong ionospheric trend in Antarctica, our next step will be the application of the spherical cap harmonics analysis to $f o F 2$ data. To achieve this goal we will apply the concept of information content $I(t)$ to the spherical cap harmonics coefficients, to look for similarities between the time scales associated to the polar ionosphere and those associated to the geomagnetic reversal.

Taking into account that several mechanisms of anthropogenic nature, such as the enhancement of the greenhouse effect or the ozone depletion, or of natural origin, such as the long-term increase of the geomagnetic activity due to internal or external forces, could influence the secular behaviour of the ionosphere, our contribution to the scientific debate on this subject can be summarized with an open question: is there a connection between the foF2 secular (stronger!) trend over Antarctica and the corresponding local contribution to the imminent (340 years!) reversal or excursion given by the southern hemisphere?

Acknowledgements. This study was supported by the Italian Program of Antarctic Researches (PNRA), in the frame of the projects "REM" and "Upper Atmosphere observations and Space Weather".

The authors acknowledge the UK ionosondes group and the World Data Centre $\mathrm{C}-1$ for providing $f o F 2$ data, the IPS (Australia) and IRF (Sweden) for providing recent $f o F 2$ data from Mawson and Lycksele, G. Fontana for the collaboration in processing the data and S. Pau and M. Pezzopane for validating Rome data.

Topical Editor M. Pinnock thanks J. Bremer and another anonymous referee for their help in evaluating this paper.

\section{References}

Alfonsi, L., De Franceschi, G., and Perrone, L.: Long-term trend in the high latitude ionosphere, Physics and Chemistry of the Earth 26/5, 303-307, 2001

Alfonsi, L., De Franceschi, G., Perrone, L., Materassi, M.: Long term trends of the critical frequency of the f2 layer at northern and southern high latitude regions, Phys. Chem. Earth, 27/6-8, 595-600, 2002.

Bremer, J.: Ionospheric trends in mid-latitudes as a possible indicator of the atmospheric greenhouse effect, J. Atmos. Terr. Phys., 54, 1505-1511, 1992.

Bremer, J.: Long-term trends in different ionospheric layers, Radio Science Bulletin, 315, 22-32, 2005.

Clilverd, M. A., Clark, T. D. G., Clarke, E., and Rishbeth, H.: Increased magnetic storm activity from 1868 to 1995, J. Atmos. Sol.-Terr. Phy., 60, 1047-1056, 1998.
Clilverd, M. A., Clark, T. D. G., Clarke, E., Rishbeth, H., and Ulich, T.: The causes of long-term change in the aa index, J. Geophys. Res., 107(A12), 1441, doi:10.1029/2001JA000501, 2002.

Clilverd, M. A., Clarke, E., Ulich, T., Linthe, J., and Rishbeth, H.: Reconstructing the long-term aa index, J. Geophys. Res., 110, A07205, doi:10.1029/2004JA010762, 2005.

Cliver, E. W. and Ling, A. G.: Secular change in geomagnetic indices and the solar open magnetic flux during the first half of the twentieth century, J. Geophys. Res., 107(A10), 1303, 2002.

Danilov, A. D.: F2 region response to geomagnetic disturbance, J. Atmos. Sol.-Terr. Phy., 63, 441-449, 2001.

De Franceschi, G., De Santis, A., and Pau, S.: Ionospheric mapping by regional spherical harmonic analysis: new developments, Adv. Space Res., 14(12), 61-64, 1994.

De Franceschi, G., Gulyaeva, T. L., Perrone, L., and Zolesi, B. MAC: An Oriented Magnetic Activity Catalogue for Ionospheric Applications, U.R.S.I. International Reference Ionosphere News Letter, 6/4, 5-6, 1999.

De Franceschi, G., Gulyaeva, T. L., Perrone, L., and Zolesi, B.: A statistical analysis of ionospheric irregularities at mid and high latitudes, Inverse Problems, 18, 67-78, 2002.

De Santis, A., De Franceschi, G., Zolesi, B., and Cander, Lj. R.: Regional modelling and mapping of the ionospheric characteristic parameters by Spherical Cap Harmonic Expansion, Adv. Space Res., 12(6), 279-282, 1992.

De Santis, A., Falcone, C., and Lowes, F. J.: Remarks on the meansquare values of the geomagnetic field and its components, Annali di Geofisica, 38(2), 167-175, 1995.

De Santis, A., Torta, J. M., and Gaya-Piqué, L. R.: The first Antarctic geomagnetic Reference Model (ARM), Geophys. Res. Lett., 29(8), 1192, doi:10.1029/2002GL014675, 2002.

De Santis, A., Tozzi, R., and Gaya-Piqué, L. R.: Information content and $K$-entropy of the present geomagnetic field, Earth Planet. Sci. Lett., 218, 269-275, 2004.

De Santis, A.: How persistent is the present trend of the geomagnetic field to decay and, possibly, to reverse?, Phys. Earth Planet. In., 162, 217-226, 2007.

Gaya-Piqué, L. R., Ravat, D., De Santis, A., and Torta, J. M.: New model alternatives for improving the representation of the core magnetic field of Antarctica, Antarct. Sci., 18(1), 101-109, 2006.

Gubbins D.: Mechanism for geomagnetic polarity reversals, Nature, 326, 167-169, 1987.

Gubbins, D., Jones, A. L., and Finlay, C. C.: Fall in Earth's magnetic field is erratic, Science, 312, 900-902, 2006.

Gulyaeva, T. L.: Forecast of recurrent magnetic storms one day in advance, Geomagnetism and Aeronomy, 42(N2), 169-174, 2002.

Lastovicka, J.: On the role of solar and geomagnetic activiy in longterm trends in the atmosphere-ionosphere system, J. Atmos. Sol.Terr. Phy., 67, 83-92, 2005.

Lastovicka, J., Mikhailov, A. V., Ulich, Th., Bremer, J., Elias, A. G., Ortiz de Adler, N., Jara, V., Abarca del Rio, R., Foppiano, A J., Ovalle, E., and Danilov, A. D.: Long-term trends in foF2: A comparison of various methods, J. Atmos. Sol.-Terr. Phy., 68/17, 1854-1870, 2006.

Lockwood, M. and Stamper, R.: Long-term drift of the coronal source magnetic flux and the total solar irradiance, Geophys. Res. Lett., 26, 2461-2464, 1999.

Lowes, F. J.: Mean square values on the sphere of spherical har- 
monic vector fields, J. Geophys. Res., 71, 2179, 1966.

Macmillan, S. and Maus, S.: International Geomagnetic Reference Field - the tenth generation, Earth Planets Space, 57, 1135-1140, 2005.

Mikhailov, A. V. and Marin, D.: Geomagnetic control of the f0F2 long-term trends, Ann. Geophys. 18, 653-665, 2000.

Mursula, K. and Martini, D.: Centennial increase in geomagnetic activity: Latitudinal differences and global estimates, J. Geophys. Res., 111, A08209, doi:10.1029/2005JA011549, 2006.

Perrone, L. and De Franceschi, G.: A correlation study between time-weighted magnetic indices and the high-latitude ionosphere, Phys. Chem. Earth, 24, 389-392, 1999.

Perrone, L., De Franceschi, G., and Gulyaeva, T.: The timeweighted magnetic indices $\operatorname{ap}(\tau), \operatorname{PC}(\tau)$ and $\operatorname{AE}(\tau)$ and their correlation to the southern high latitude ionosphere, Phys. Chem. Earth, 26/5, 331-334, 2001.

Piggott, W. R. and Rawer, K.: U.R.S.I. Handbook of Ionogram Interpretation and Reduction, World Data Center A for SolarTerrestrial Physics, NOAA, Boulder, Colorado, 1972.

Rajaram, G., Arun, T., Dhar, A., and Patil, A. G.: Rapid decrease in total magnetic field $\mathrm{F}$ at Antarctic stations-its relationship to core-mantle features, Antarct. Sci., 14(1), 61-68, 2002.
Richardson, I. G., Cliver, E. W., and Cane, H. V.: Long-term trends in interplanetary magnetic field strength and solar wind structure during the twentieth century, J. Geophys. Res., 107(A10), 1304, doi:10.1029/2001JA000507, 2002.

Rishbeth, H.: The quadrupole ionosphere, Ann. Geophys., 3, $293-$ 298, 1985, http://www.ann-geophys.net/3/293/1985/.

Rishbeth, H.: Long-term changes in the ionosphere, Adv. Space Phys., 20, 2149-2155, 1997.

Shannon, C.: A mathematical theory of communication, Bell Syst. Tech. J., 27, 379-423, 623-656, 1948.

Svalgaard, L., Cliver, E., W., and Le Sager, P.: IHV : A new longterm geomagnetic index, Adv. Space Res., 34, 436-439, 2004.

Ulich, T., Clilverd, M. A., and Rishbeth, H.: Determining LongTerm Change in the Ionosphere EOS, Transactions American Geophysical Union, 84, 52, 581, 2003.

Wrenn, G. L.: Time-Wighted Accumulations $\operatorname{ap}(\tau)$ and $\operatorname{Kp}(\tau)$, J. Geophys. Res., 92, 125-129, 1987.

Wu, J. and Wilkinson, P. J.: Time-weighted indices as predictors of ionospheric behaviour, J. Atmos. Terr. Phy., 57, 1736-1770, 1995. 